\title{
Predictors of mortality in acute lung injury during the era of lung protective ventilation
}

\author{
E Seeley, ${ }^{1}$ D F McAuley, ${ }^{2}$ M Eisner, ${ }^{1}$ M Miletin, ${ }^{1,3}$ M A Matthay, ${ }^{1}$ R H Kallet ${ }^{4}$
}

${ }^{1}$ Departments of Medicine and Anesthesia, Cardiovascular Research Institute, University of California, San Francisco, California, USA; ${ }^{2}$ Respiratory Medicine Research Group, Queen's University of Belfast, Belfast, Northern Ireland, UK;

${ }^{3}$ Department of Medicine, William Osler Health Centre, Toronto, Canada; ${ }^{4}$ Department of Anesthesia, University of California, San Francisco at San Francisco General Hospital, San Francisco, California, USA

\section{Correspondence to:}

Dr E J Seeley, University of California, San Francisco, 505

Parnassus Ave, Box 0130, San Francisco, CA 94143, USA; eric.seeley@ucsf.edu

Received 22 November 2007 Accepted 2 June 2008 Published Online First 19 June 2008

\section{ABSTRACT}

Background: Lung protective ventilation has been widely adopted for the management of acute lung injury (ALI) and acute respiratory distress syndrome (ARDS). Consequently, ventilator associated lung injury and mortality have decreased. It is not known if this ventilation strategy changes the prognostic value of previously identified demographic and pulmonary predictors of mortality, such as respiratory compliance and the arterial oxygen tension to inspired oxygen fraction ratio $\left(\mathrm{PaO}_{2} / \mathrm{FiO}_{2}\right)$.

Methods: Demographic, clinical, laboratory and pulmonary variables were recorded in 149 patients with ALI/ ARDS. Significant predictors of mortality were identified in bivariate analysis and these were entered into multivariate analysis to identify independent predictors of mortality.

Results: Hospital mortality was $41 \%$. In the bivariate analysis, 17 variables were significantly correlated with mortality, including age, APACHE II score and the presence of cirrhosis. Pulmonary parameters associated with death included $\mathrm{PaO}_{2} / \mathrm{FiO}_{2}$ and oxygenation index ((mean airway pressure $\left.\left.\times \mathrm{FiO}_{2} \times 100\right) \div \mathrm{PaO}_{2}\right)$. In unadjusted analysis, the odds ratio (OR) of death for $\mathrm{PaO}_{2} / \mathrm{FiO}_{2}$ was 1.57 (Cl 1.12 to 3.04 ) per standard deviation decrease. However, in adjusted analysis, $\mathrm{PaO}_{2} / \mathrm{FiO}_{2}$ was not a statistically significant predictor of death, with an OR of 1.29 (Cl 0.82 to 2.02). In contrast, oxygenation index (OI) was a statistically significant predictor of death in both unadjusted analysis (OR 1.89 (Cl 1.28 to 2.78)) and in adjusted analysis (OR 1.84 (Cl 1.13 to 2.99)).

Conclusions: In this cohort of patients with ALL/ARDS, Ol was an independent predictor of mortality, whereas $\mathrm{PaO}_{2} /$ $\mathrm{FiO}_{2}$ was not. Ol may be a superior predictor because it integrates both airway pressure and oxygenation into a single variable.

Despite advances in our understanding of the pathophysiology and treatment of acute lung injury (ALI) and acute respiratory distress syndrome (ARDS), mortality remains high; approximately $30-60 \%$ of patients die before hospital discharge. ${ }^{1-3}$ Lung protective ventilation, a strategy that targets lower tidal volumes $(\mathrm{Vt})$ and limits plateau pressure ( $\mathrm{P}_{\text {plat }}$ ) to less than $30 \mathrm{~cm} \mathrm{H}_{2} \mathrm{O}$ is the only clinical intervention that has shown a mortality benefit in large randomised trials. ${ }^{45}$

Observational studies performed before widespread application of lung protective ventilation identified demographic, pulmonary specific and clinical variables that predict mortality in ALI/ ARDS. $^{36-9}$ These included age, Severe Acute Physiology Score (SAPS II), Acute Physiology and Chronic Health Evaluation (APACHE II) score, cirrhosis, immunosuppression and pulmonary specific variables, including the arterial oxygen tension to fraction of inspired oxygen $\left(\mathrm{PaO}_{2} / \mathrm{FiO}_{2}\right)$ ratio, ${ }^{9}$ respiratory system compliance $(\mathrm{Crs})^{3}$ and oxygenation index (OI). ${ }^{7}$ To our knowledge, no large study of mortality predictors has been conducted in North America since the implementation of the lung protective ventilation. Thus we conducted a retrospective study of these variables to identify early predictors of mortality in ALI/ ARDS after adoption of lung protective ventilation. We hypothesised that this ventilation strategy may attenuate the predictive value of previously identified pulmonary specific measures.

\section{METHODS \\ Subjects}

We studied patients in both medical and surgical intensive care units identified prospectively as part of ongoing clinical trials of ALI/ARDS between 1 July 2002 and 30 June 2003. The study was done at the University of California Moffitt-Long Hospital, a tertiary university referral centre, and at San Francisco General Hospital, a large, inner city hospital and level 1 trauma centre. Retrospective data collection was approved by the institutional review board of the University of California, San Francisco and given the retrospective nature of this study, the requirement for written informed consent was waived. Patients were 18 years of age or older, had received mechanical ventilation and met the North American-European consensus conference definition for ALI/ARDS. ${ }^{10}$ No exclusion criteria were used. Ventilator management was at the discretion of the critical care team. However, both hospitals had implemented the lung protective ventilation protocol of the ARDS Net trial.

\section{Data collection}

The plan for data collection and the data analysis strategy were defined prospectively, before review of the medical records began. Data were recorded at a daily reference time between 06:00 and 10:00. Arterial blood gases $(\mathrm{ABG})$ used to calculate $\mathrm{PaO}_{2} /$ $\mathrm{FiO}_{2}$ were drawn during this reference period. It is the policy of the respiratory care departments that $A B G$ are not obtained within 20 min of suctioning and recruitment manoeuvres are not standard treatment in our hospital system and were unlikely to confound the $\mathrm{ABG}$ measurements. A reference quasi-static respiratory compliance (Crs) was found to reflect average daily $\mathrm{Crs}$ in a subset of subjects. ${ }^{11}$

Clinical data were abstracted from the medical record for up to 7 days or until death or extubation, whichever occurred first. These data included the aetiology of ALI/ARDS, coexisting medical illnesses, use of glucocorticoids or other causes of immunosuppression, fluid intake/output and 
Table 1 Clinical characteristics of 149 with patients with ALI/ARDS

\begin{tabular}{|c|c|}
\hline Characteristic & \\
\hline Age (years) & $48.6(17.4)$ \\
\hline \multicolumn{2}{|l|}{ Gender } \\
\hline Female (n (\%)) & $49(33)$ \\
\hline Male (n (\%)) & $100(67)$ \\
\hline SAPS ॥ & $44.3(14.6)$ \\
\hline APACHE ॥ & $19.9(7.8)$ \\
\hline LIS & $2.6(0.5)$ \\
\hline \multicolumn{2}{|l|}{ Mechanical ventilation variables } \\
\hline $\mathrm{Vt}(\mathrm{ml} / \mathrm{kg}$ PBW) & $7.6(2.1)$ \\
\hline PEEP $\left(\mathrm{cm} \mathrm{H}_{2} \mathrm{O}\right)$ & $7.6(3.0)$ \\
\hline$f$ & $22.5(8.1)$ \\
\hline $\mathrm{FiO}_{2}$ & $0.8(0.2)$ \\
\hline $\mathrm{PaO}_{2} / \mathrm{FiO}_{2}(\mathrm{kPa})$ & $19.2(9.5)$ \\
\hline Ol $\left(\mathrm{cm} \mathrm{H}_{2} \mathrm{O} / \mathrm{kPa}\right)$ & $89.3(59.3)$ \\
\hline $\mathrm{pH}$ & $7.34(0.1)$ \\
\hline Base deficit & $-3.44(6.4)$ \\
\hline $\operatorname{Crs}\left(\mathrm{ml} / \mathrm{cm} \mathrm{H} \mathrm{H}_{2} \mathrm{O}\right)$ & $28.2(10.3)$ \\
\hline \multicolumn{2}{|l|}{ Aetiology of ALL/ARDS (n (\%)) } \\
\hline Pneumonia & $47(32)$ \\
\hline Sepsis & $33(22)$ \\
\hline Aspiration & $16(11)$ \\
\hline Probable TRALI & $11(7)$ \\
\hline Trauma & $10(7)$ \\
\hline Pancreatitis & $8(5)$ \\
\hline Other or unknown & $24(16)$ \\
\hline \multicolumn{2}{|l|}{ Underlying medical conditions (n (\%)) } \\
\hline Cirrhosis & $22(14)$ \\
\hline HIV/AIDS & $18(12)$ \\
\hline Heart transplant & $8(5)$ \\
\hline Metastatic cancer (solid tumour) & $7(4)$ \\
\hline Haematological cancer & $5(3)$ \\
\hline Bone marrow transplantation & $3(2)$ \\
\hline
\end{tabular}

Data are mean (SD) or $\mathrm{n}(\%)$.

AIDS, acquired immunodeficiency syndrome; ALI, acute lung injury; ARDS, acute respiratory distress syndrome; APACHE, Acute Physiology and Chronic Health Evaluation; Crs, respiratory system compliance; $\mathrm{f}$, respiratory frequency; $\mathrm{FiO}_{2}$, inspired oxygen fraction; HIV, human immunodeficiency virus; LIS, lung injury score; $\mathrm{Ol}$, oxygenation index; $\mathrm{PaO}_{2}$, arterial oxygen partial pressure; $\mathrm{PBW}$, predicted body weight; PEEP, positive end expiratory pressure; SAPS II, Severe Acute Physiology Score II; TRALI, transfusion related lung injury; Vt, tidal volume.

balance, vital signs and chest radiographic findings. The clinical disorder associated with ALI/ARDS was considered primary if the cause was pneumonia, aspiration, direct lung trauma or inhalational injury. All other causes were considered secondary. Of the 149 patients included in the multivariate logistic regression analysis, 22 patients had partially missing data.

Laboratory data included electrolytes, blood urea nitrogen, creatinine, white blood cell count and haematocrit. Mechanical ventilation variables included ABG, peak inspiratory pressure, $\mathrm{P}_{\text {plat }}$, positive end expiratory pressure (PEEP), mean airway pressure (Paw), Vt both in $\mathrm{ml}$ and $\mathrm{ml} / \mathrm{kg}$ predicted body weight $(\mathrm{PBW})$, respiratory frequency $(\mathrm{f})$ and minute ventilation $\left(\mathrm{V}_{\mathrm{E}}\right)$. Calculated variables included the lung injury score, ${ }^{12}$ APACHE II, ${ }^{13}$ SAPS II, ${ }^{14} \mathrm{PaO}_{2} / \mathrm{FiO}_{2}$, and $\mathrm{Crs}$. OI was calculated as: (mean airway pressure $\left.\times \mathrm{FiO}_{2} \times 100\right) \div \mathrm{PaO}_{2} .{ }^{9}$ Higher values of OI indicate poorer oxygenation. For patients with trauma induced ALI/ ARDS, the Injury Severity Score ${ }^{15}$ was also determined.

\section{Statistical analysis}

Death prior to hospital discharge was the primary outcome variable in this study. Patients were followed until death or discharge from hospital. Patients were categorised as survivors or non-survivors and the variables enumerated above were compared using bivariate analysis. Continuous normally distributed variables were compared using a Student's t test and categorical variables were compared using a $\chi^{2}$ test. Select variables that were statistically significant, or of a priori clinical significance, were then introduced into a forward, stepwise, logistic regression model. SAS computer software (SAS Institute, Cary, North Carolina, USA) was used for statistical analysis. All interval data are presented as mean (SD). The goodness-of-fit of the logistic regression model was assessed with the Hosmer-Lemeshow test. Standard regression diagnostics and goodness-of-fit testing indicated that the logistic regression models were adequate. Results were considered to be statistically significant if $p<0.05$.

\section{RESULTS}

Between 1 July 2002 and 30 June 2003, 149 patients with ALI/ ARDS were identified at the two hospitals and their data were incorporated into this study (table 1). Patients with ALI/ARDS had moderately severe lung injury characterised by a low Crs and marked impairment in oxygenation (average $\mathrm{PaO}_{2} /$ $\mathrm{FiO}_{2} 19.2 \mathrm{kPa}$ ). On the day of ALI/ARDS diagnosis, patients were ventilated with an average of 7.6 (SD 2.1) $\mathrm{ml} / \mathrm{kg}$ PBW that subsequently decreased to $7.0(2.1) \mathrm{ml} / \mathrm{kg}$ PBW on day 2, 6.8 (1.8) $\mathrm{ml} / \mathrm{kg}$ PBW on day 3 and $6.6(1.4) \mathrm{ml} / \mathrm{kg}$ PBW on day 4.

ALI/ARDS was the result of direct pulmonary injury in $48 \%$ of patients, while $52 \%$ had an indirect or extrapulmonary cause. At enrolment, $19 \%$ of patients had a $\mathrm{PaO}_{2} / \mathrm{FiO}_{2}$ between 27 and $41 \mathrm{kPa}(200-300 \mathrm{~mm} \mathrm{Hg})$ and $81 \%$ had a $\mathrm{PaO}_{2} / \mathrm{FiO}_{2}<27 \mathrm{kPa}$ (200 mm Hg). All but one patient initially diagnosed with ALI developed ARDS $\left(\mathrm{PaO}_{2} / \mathrm{FiO}_{2}<27 \mathrm{kPa}\right)$ within $48 \mathrm{~h}$.

The overall hospital mortality in our cohort of patients with ALI/ARDS was 41\% (61/149; 95\% confidence interval (CI) 33\% to $49 \%$ ), which was higher, but not significantly different from the mortality predicted by APACHE II (36\%) and SAPS II (33\%). Most patients had a variety of chronic comorbid conditions: $26 \%$ were immunosuppresed and $15 \%$ had cirrhosis. Patients originally diagnosed with ALI had a lower mortality compared with patients with ARDS ( $31 \%$ vs 44\%), but this difference was not statistically significant $(p=0.21)$. There was no significant difference in mortality between patients with a primary or secondary cause of ALI/ARDS. Although women accounted for only 34\% of study subjects (50/149), there was a suggestion of increased mortality compared with men: $51 \%(25 / 49)$ vs $36 \%(36 / 99)$, respectively $(p=0.06)$. Of note, on entry into the study, women had a higher average APACHE II score than men (22 vs 18; $p<0.01$ ). Nonsurvivors had a lower $\mathrm{PaO}_{2} / \mathrm{FiO}_{2}$ and arterial $\mathrm{pH}$, a more negative base deficit and a higher OI (table 2).

In the bivariate analysis, 17 variables were significantly correlated with mortality, including increased age, cirrhosis, higher APACHE II and SAPS II (table 2). Pulmonary variables correlated with death included an elevated OI (73.5 vs $111.8 \mathrm{~cm}$ $\mathrm{H}_{2} \mathrm{O} / \mathrm{kPa} ; \mathrm{p}<0.001$ ), decreased $\mathrm{PaO}_{2} / \mathrm{FiO}_{2}$ (both at onset of lung injury and worst value in the first $24 \mathrm{~h}$ after onset of lung injury), increased $\mathrm{FiO}_{2}$, and lower $\mathrm{PaO}_{2}$. In contrast, $\mathrm{Vt}, \mathrm{f}, \mathrm{Crs}, \mathrm{P}_{\text {plat }}$ and PEEP were not statistically correlated with death. Both the presence of haemodynamic compromise (lowest systolic blood pressure, diastolic blood pressure and mean arterial pressure) and acidosis on the day of ALI/ARDS onset were significantly correlated with death. Developing ALI/ARDS from trauma predicted a better prognosis, with a mortality of only $15 \%$.

In a multivariate logistic regression model, both $\mathrm{PaO}_{2} / \mathrm{FiO}_{2}$ and OI were predictive of death in unadjusted analysis (table 3). Compliance was not statistically predictive of death in 
Table 2 Variables associated with an increased risk of death: bivariate analysis

\begin{tabular}{|c|c|c|c|c|}
\hline & $\begin{array}{l}\text { Survivors }(\mathrm{n}=88) \\
\text { Mean }(\mathrm{SD})\end{array}$ & $\begin{array}{l}\text { Non-survivors }(n=61) \\
\text { Mean (SD) }\end{array}$ & $\begin{array}{l}\text { Mean difference/ } \\
\text { OR }(95 \% \mathrm{CI})\end{array}$ & $\begin{array}{l}\text { p Value } \\
\text { between groups }\end{array}$ \\
\hline Age (years) & $44.2(16.7)$ & $55.1(17.0)$ & $10.6(5.2$ to 16.1$)$ & $<0.001$ \\
\hline Trauma & $11(12 \%)^{*}$ & $2(3 \%)^{*}$ & $0.3(0.1$ to 1.3$)$ & $<0.05$ \\
\hline Gender (\% female) & $24(27 \%)^{*}$ & $25(41 \%)^{*}$ & 1.8 (0.9 to 3.7$)$ & $<0.1$ \\
\hline OI (cm H$\left.{ }_{2} \mathrm{O} / \mathrm{kPa}\right)$ & $73.5(42.0)$ & $111.8(70.5)$ & 33.8 (15 to 52.5$)$ & $<0.001$ \\
\hline $\mathrm{PaO}_{2} / \mathrm{FiO}_{2}(\mathrm{kPa})$ & $20.7(8.3)$ & $16.4(8.3)$ & $-2.5(-5.8$ to -0.7$)$ & 0.003 \\
\hline $\mathrm{FiO}_{2}$ & $0.7(0.2)$ & $0.8(0.2)$ & $0.04(-0.03$ to 0.1$)$ & 0.01 \\
\hline $\mathrm{PaO}_{2}(\mathrm{kPa}) \uparrow$ & $10.9(4.4)$ & $9.6(2.9)$ & 1.2 (3.2 to 0.8 ) & 0.05 \\
\hline $\mathrm{Vt}(\mathrm{ml} / \mathrm{kg} \mathrm{PBW})$ & $7.9(1.9)$ & $7.2(2.3)$ & $-0.5(-1.2$ to 0.2$)$ & 0.06 \\
\hline f Value & $21.6(7.6)$ & $24.1(8.5)$ & $1.9(-0.8$ to 4.7$)$ & 0.07 \\
\hline $\mathrm{P}_{\text {plat }}\left(\mathrm{cm} \mathrm{H}_{2} \mathrm{O}\right)$ & $25.5(6.0)$ & $27.6(7.6)$ & $2.1(-0.1$ to 4.6$)$ & 0.09 \\
\hline Mean Paw $\left(\mathrm{cm} \mathrm{H}_{2} \mathrm{O}\right)$ & $14.0(4.0)$ & $15.3(5.5)$ & $0.9(-.9$ to 2.6$)$ & 0.1 \\
\hline $\operatorname{Crs}\left(\mathrm{ml} / \mathrm{cm} \mathrm{H}_{2} \mathrm{O}\right)$ & $29.2(9.7)$ & $26.7(11.2)$ & $-2.0(-5.4$ to 1.5$)$ & 0.2 \\
\hline PEEP & $7.3(2.8)$ & $7.9(3.3)$ & $0.6(-0.5$ to 1.6$)$ & 0.3 \\
\hline SAPS II & $39.2(13.7)$ & $50.6(12.4)$ & 10.5 (5.8 to 15.3$)$ & $<0.001$ \\
\hline APACHE II & $17.4(7.1)$ & $22.5(7.0)$ & 4.6 (2.1 to 7.2$)$ & $<0.001$ \\
\hline $\mathrm{pH}$ & $7.37(0.1)$ & $7.30(0.1)$ & $-0.06(-0.1$ to -0.02$)$ & 0.001 \\
\hline Base deficit-day 1 & $-2.15(5.78)$ & $-4.97(6.70)$ & $-1.5(-4.0$ to 0.9$)$ & 0.008 \\
\hline Cirrhosis (n (\%)) & $7(8)^{*}$ & $14(25)^{*}$ & 3.7 (1.4 to 9.2$)$ & 0.005 \\
\hline
\end{tabular}

\footnotetext{
*Percentages of row total.

$\uparrow$ Value at time of diagnosis of lung injury. In column 4, continuous values are displayed as mean differences and categorical values are displayed as ORs.

APACHE, Acute Physiology and Chronic Health Evaluation; Crs, respiratory system compliance; f, respiratory frequency;

$\mathrm{FiO}_{2}$, inspired oxygen fraction; $\mathrm{Ol}$, oxygenation index; $\mathrm{PaO}_{2}$, arterial oxygen partial pressure; PBW, predicted body weight;

PEEP, positive end expiratory pressure; mean Paw, mean airway pressure; $P_{\text {plat }}$, end inspiratory plateau pressure; SAPS II, Severe Acute Physiology Score II; Vt, tidal volume.
}

unadjusted (OR 1.22, 95\% CI 0.86 to 1.72) or adjusted (OR 1.23, $95 \%$ CI 0.77 to 1.96 ) analysis. When adjusted for variables that were significant in bivariate analysis as well as other variables defined a priori (presence of chronic obstructive pulmonary disease, pneumonia, vasopressor use and gender), $\mathrm{PaO}_{2} / \mathrm{FiO}_{2}$ was no longer a statistically significant predictor of death (OR 1.30, $95 \%$ CI 0.83 to 2.04$)$. In contrast, OI remained a robust predictor in adjusted analysis (OR 1.85, 95\% CI 1.14 to 3.01 ). We also carried out multivariate logistic regression using SAPS II instead of APACHE II. Overall, the results were similar; OI was still a significant predictor of death in multivariate adjusted analysis (OR 2.07, 95\% CI 1.25 to 3.22) but $\mathrm{PaO}_{2} / \mathrm{FiO}_{2}$ was not (OR $1.32,95 \%$ CI 0.84 to 2.06 ).

\section{DISCUSSION}

In this retrospective observational study, we aimed to identify early predictors of mortality in patients managed with lung protective ventilation. In particular, we hoped to determine if Crs would still be predictive of mortality, as we found during traditional Vt $(10 \mathrm{ml} / \mathrm{kg})$ ventilation in the late $1990 \mathrm{s.}^{3}$ Our primary finding was that OI, which relates severity of oxygenation impairment $\left(\mathrm{PaO}_{2}\right)$ to the intensity of mechanical

Table 3 Unadjusted and multivariate adjusted odds ratio of death for OI, $\mathrm{PaO}_{2} / \mathrm{FiO}_{2}$ and $\mathrm{Crs}$

\begin{tabular}{lll}
\hline & $\begin{array}{l}\text { Unadjusted } \mathbf{~ O R} \\
\text { (95\% CI) }\end{array}$ & $\begin{array}{l}\text { Multivariate } \mathbf{O R}^{*} \\
\mathbf{( 9 5 \% ~ C I )}\end{array}$ \\
\hline OI (per SD increase) & $1.89(1.28$ to 2.78$)$ & $1.84(1.12$ to 3.04$)$ \\
$\mathrm{PaO}_{2} / \mathrm{FiO}_{2}$ (per SD decrease) & $1.57(1.09$ to 2.26$)$ & $1.28(0.82$ to 2.02$)$ \\
Crs (per SD decrease) & $1.22(0.86$ to 1.72$)$ & $1.23(0.77$ to 1.96$)$ \\
\hline
\end{tabular}

OR per standard deviation increase in OI (SD 57.8) and decrease in $\mathrm{PaO}_{2} / \mathrm{FiO}_{2}$ (SD 8.3) and $\mathrm{Crs}(\mathrm{SD}=10.3)$. Data were partially missing for 22 patients.

${ }^{*}$ Controlled for age, sex, presence of chronic obstructive pulmonary disease, pneumonia, trauma, use of vasopressors, $\mathrm{pH}$ and APACHE II score.

Crs, compliance; Ol, oxygenation index; $\mathrm{PaO}_{2} / \mathrm{FiO}_{2}$, ratio of arterial oxygen partial pressure to inspired oxygen fraction. ventilation $\left(\mathrm{FiO}_{2}\right.$ and mean airway pressure) was a predictor of death, even in an adjusted multivariate analysis.

Over the past 20 years, several studies have reported that mortality from ALI/ARDS has decreased, ${ }^{16-20}$ while the only therapy shown to have a mortality benefit is lung protective ventilation. ${ }^{4}$ Likewise, observational studies of ALI/ARDS done at the University of California San Francisco hospital system over the past 15 years have also shown a decline in mortality. In the early 1990s, Doyle and colleagues ${ }^{2}$ reported hospital mortality of $58 \%$ for patients with ALI/ARDS whereas by the late 1990s Nuckton and colleagues ${ }^{3}$ found that mortality in patients with ARDS alone was $42 \%$. In this study of patients with ALI/ARDS, mortality was $41 \%$.

Mean Vt on the first day of ALI/ARDS was $7.6 \mathrm{ml} / \mathrm{kg}$ PBW which decreased to $6.6 \mathrm{ml} / \mathrm{kg}$ PBW by day 4 . This level was higher than the Vt levels achieved during the ARDS Net study. In another observational study where the ARDS Net protocol was more strictly adhered to, as evidenced by an average Vt of $6.2 \mathrm{ml} / \mathrm{kg}$ PBW that was maintained over the first week of ALI/ ARDS, hospital mortality was $32 \%$ despite the presence of some of the same comorbid conditions. ${ }^{21}$ This finding suggests the possibility that the relatively higher mortality, despite the intention to use lung protective ventilation, may be a result of delayed recognition of ARDS or less rigorous adherence to the ARDS Net goal of a Vt of $6 \mathrm{ml} / \mathrm{kg}$ PBW.

In general, non-pulmonary variables identified as predictors of mortality in studies performed prior to lung protective ventilation were also predictive of death in our study. These variables included age, APACHE II, SAPS II, cirrhosis and $\mathrm{pH}^{2}{ }^{27}$ In contrast, many of the pulmonary specific variables identified in previous studies, including $\mathrm{Crs},{ }^{3} \mathrm{P}_{\text {plat }}{ }^{22}$ and $\mathrm{Vt}^{3}{ }^{3}$ were not significantly associated with death in our study. Limiting $\mathrm{Vt}$ and $\mathrm{P}_{\text {plat }}$ with lung protective ventilation likely attenuates early alveolar volutrauma, which has been shown in animal models to have early effects on lung vascular permeability and thus compliance..$^{22}$ It may be that the predictive value of Crs observed 
in the study by Nuckton and colleagues ${ }^{3}$ reflected an injurious ventilation strategy and that lung protective ventilation alleviates this early ventilator associated lung injury.

The value of $\mathrm{PaO}_{2} / \mathrm{FiO}_{2}$ as an early predictor of death in ALI/ ARDS is uncertain. Bone and colleagues ${ }^{9}$ observed that although $\mathrm{PaO}_{2} / \mathrm{FiO}_{2}$ was not different at onset of ARDS, survivors were characterised by a steady increase in $\mathrm{PaO}_{2} / \mathrm{FiO}_{2}$ over the first week of conventional therapy. Likewise, in a recent review of 13 large observational trials, Ware ${ }^{23}$ found that $\mathrm{PaO}_{2} / \mathrm{FiO}_{2}$ at the onset of ALI/ARDS did not predict clinical outcome, but a persistently low $\mathrm{PaO}_{2} / \mathrm{FiO}_{2}$ was associated with worse outcomes and may be a marker of failure to respond to conventional therapy.

In contrast with the $\mathrm{PaO}_{2} / \mathrm{FiO}_{2}$, OI was a robust predictor of mortality, even in the adjusted analysis. This finding supports the results of some prior investigators, although most large observational studies have not measured or reported OI. ${ }^{37}$ OI may be a better predictor of death than $\mathrm{PaO}_{2} / \mathrm{FiO}_{2}$ because it accounts for changes in mean airway pressure as well as $\mathrm{FiO}_{2}$. OI has received more attention in the paediatric literature where Trachsel and colleagues ${ }^{24}$ found that OI, measured at any time during hospitalisation, was the best pulmonary predictor of death in a group of paediatric patients with acute hypoxic respiratory failure. In addition, OI was identified as the best bedside surrogate for intrapulmonary shunt, the primary pathophysiological derangement of ARDS.$^{25}$ Lastly, Bayrakci et al found that an OI $>249 \mathrm{~cm} \mathrm{H}_{2} \mathrm{O} / \mathrm{kPa}\left(33.2 \mathrm{~cm} \mathrm{H} \mathrm{H}_{2} \mathrm{O} / \mathrm{mm} \mathrm{Hg}\right)$ is a good predictor of the development of chronic lung disease or death in neonates with hypoxaemic respiratory failure. They advocate an $\mathrm{OI}>249 \mathrm{~cm} \mathrm{H}_{2} \mathrm{O} / \mathrm{kPa}\left(33.2 \mathrm{~cm} \mathrm{H} \mathrm{H}_{2} \mathrm{O} / \mathrm{mmHg}\right)$ as a cut-off for initiating ECMO in this patient population. ${ }^{26}$

The most recent AECC definition discriminates ALI from ARDS based on the level of the $\mathrm{PaO}_{2} / \mathrm{FiO}_{2} \cdot{ }^{10}$ The utility of this distinction in predicting morbidity and mortality and in guiding clinical decision making is uncertain. We found no significant difference in mortality between patients originally diagnosed with ALI and those diagnosed with ARDS. In addition, we found that $97 \%(28 / 29)$ of patients originally diagnosed with ALI eventually develop ARDS. A recent multicentre European study involving 463 patients with ALI or $\mathrm{ARDS}^{27}$ found that $54 \%$ of patients initially diagnosed with ALI eventually progress to ARDS. Furthermore, patients that progressed to ARDS $\left(\mathrm{PaO}_{2} / \mathrm{FiO}_{2} \leqslant 27 \mathrm{kPa}\right)$ had a significantly higher mortality than those who did not. In addition, several other recent studies found no difference in mortality between patients with ALI or ARDS at initial diagnosis. ${ }^{2}{ }^{16}$ Likewise, a recent study ${ }^{28}$ with 1113 ALI/ARDS patients reported that there was no statistically significant mortality difference between patients presenting with ALI (38.5\%) or ARDS (41.1\%). However, the subset of patients who did not progress to a $\mathrm{PaO}_{2} / \mathrm{FiO}_{2}<27$ by day 3 or 7 had a statistically lower mortality of $29 \%$.

The AECC definition of ALI/ARDS was an important step toward standardising a heterogeneous group of patient with lung injury. However, as discussed above, the separation of patients into ALI and ARDS may be of limited prognostic and therapeutic utility. The variability in outcomes of patients with a $\mathrm{PaO}_{2} / \mathrm{FiO}_{2}<41 \mathrm{kPa}$ may be in large part a result of differences in the timing of $\mathrm{PaO}_{2}$ measurements and the relationship of this measurement to the level of PEEP. Estenssoro and colleagues ${ }^{29}$ illustrated this in a study of 49 patients in which $\mathrm{PaO}_{2} / \mathrm{FiO}_{2}$ ratios were measured at the time of diagnosis on zero end expiratory pressure, and over the next $24 \mathrm{~h}$ at a level of PEEP determined by the treating clinician. The average $\mathrm{PaO}_{2} / \mathrm{FiO}_{2}$ at the time of diagnosis was $16.1 \mathrm{kPa}(121 \mathrm{~mm} \mathrm{Hg})$ at $0 \mathrm{~cm} \mathrm{H} \mathrm{H}_{2} \mathrm{O}$ end expiratory pressure, which then increased with increasing
PEEP over the next $24 \mathrm{~h}$. At $6 \mathrm{~h}$, half of the patients no longer met the AECC definition of ARDS, and nearly two-thirds no longer met the definition after $24 \mathrm{~h}$ (average $\mathrm{PaO}_{2} / \mathrm{FiO}_{2}$ after $24 \mathrm{~h}$ was $31.2 \mathrm{kPa}\left(234 \mathrm{~mm} \mathrm{Hg}\right.$ ) with PEEP of $\left.12.8 \mathrm{~cm} \mathrm{H}_{2} \mathrm{O}\right)$. If the AECC definition of ALI is revised, measurement of $\mathrm{PaO}_{2}$ at a set level of PEEP or the inclusion of $\mathrm{OI}$ into the definition may better risk stratify patients.

There are some limitations of our study. Enrolment of patients was carried out at only two study centres, although one was a university tertiary care hospital and the other a citycounty medical centre. This study included 149 patients, which was large enough to identify statistical differences for several pulmonary and non-pulmonary variables, but the statistical power was not sufficient to detect differences between subsets of patients. In particular, our analysis of progression from ALI to ARDS may be limited by small sample size. In addition, power may have been inadequate to detect the impact of $\mathrm{PaO}_{2} / \mathrm{FiO}_{2}$ and Crs. Moreover, many patients in this study did not achieve the lung protective ventilation goal of a $\mathrm{Vt}$ of $6 \mathrm{ml} / \mathrm{kg}$. Tidal volumes were, however, uniformly lower compared with studies performed before the era of lung protective ventilation, and they were progressively reduced over the first 4 days after the diagnosis of ALI/ARDS. Lastly, there was a small amount of missing data in our database; no more than 10 patients had missing data for bivariate analysis and 22 patients had partially missing data in the multivariate model.

In summary, we conducted a study of early predictors of mortality in patients with ALI/ARDS after widespread adoption of lung protective ventilation. We found that demographic and laboratory variables identified in prior studies, including age, APACHE II, cirrhosis and $\mathrm{pH}$ are still predictive of death. In contrast, several pulmonary specific variables identified in previous studies, including Crs, $\mathrm{P}_{\text {plat }}$ and $\mathrm{Vt}$, were not predictive of death. Although $\mathrm{PaO}_{2} / \mathrm{FiO}_{2}$ was predictive of death in bivariate analysis, it was not statistically predictive in multivariate adjusted analysis. Importantly, we found that OI was the best bedside pulmonary predictor of mortality, and its predictive ability was sustained in multivariate analysis. OI may be superior to $\mathrm{PaO}_{2} / \mathrm{FiO}_{2}$ in predicting mortality because it integrates the important relationship between airway pressure and oxygenation into a single variable. Based on these results, OI may be a useful marker to identify subsets of patients with a poorer prognosis who might benefit from experimental therapies for ALI/ARDS.

\section{Funding: Funded by NHLBI R01 HL51856.}

\section{Competing interests: None.}

Ethics approval: Retrospective data collection was approved by the institutional review board of the University of California, San Francisco.

\section{REFERENCES}

1. Hudson LD, Milberg JA, Anardi D, et al. Clinical risks for development of the acute respiratory distress syndrome. Am J Respir Crit Care Med 1995;151:293-301.

2. Doyle RL, Szaflarski N, Modin GW, et al. Identification of patients with acute lung injury: predictors of mortality. Am J Respir Crit Care Med 1995;152:1818-24.

3. Nuckton TJ, Alonso JA, Kallet RH, et al. Pulmonary dead-space fraction as a risk factor for death in the acute respiratory distress syndrome. N Engl J Med 2002;346:1281-6.

4. The Acute Respiratory Distress Syndrome Network. Ventilation with lower tidal volumes as compared with traditional tidal volumes for acute lung injury and the acute respiratory distress syndrome. N Engl J Med 2000;342:1301-8.

5. Acute Respiratory Distress Syndrome Network. Higher versus lower positive end-expiratory pressures in patients with the acute respiratory distress syndrome. N Engl J Med 2004;351:327-36.

6. Zilberberg MD, Epstein SK. Acute lung injury in the medical ICU: comorbid conditions, age, etiology and hospital outcome. Am J Respir Crit Care Med 1998;157:1159-64. 
7. Monchi M, Bellenfant F, Cariou A, et al. Early predictive factors of survival in the acute respiratory distress syndrome: a multivariate analysis. Am J Respir Crit Care Med 1998;158:1076-81.

8. Ely WE, Wheeler AP, Thompson BT, et al. Recovery rate and prognosis in older persons who develop lung injury and the acute respiratory distress syndrome. Ann Intern Med 2002;136:25-36.

9. Bone RC, Maunder R, Slotman G, et al. An early test of survival in patients with the adult respiratory distress syndrome: the $\mathrm{PaO}_{2} / \mathrm{FiO}_{2}$ ratio and its differential response to conventional therapy. Chest 1989;96:849-51.

10. Bernard GR, Artigas A, Brigham KL, et al. Report of the American-European consensus conference on acute respiratory distress syndrome: Definitions mechanisms, relevant outcomes, and clinical trials coordination. Am J Respir Crit Care Med 1994;149:818-24.

11. Kallet RH, McAuley DF, Milliten M, et al. Reference respiratory system compliance (Crs) measurements as a reflection of average Crs in acute lung injury (ALI) and acute respiratory distress syndrome (ARDS). Am J Respir Crit Care Med 2004:169:A780.

12. Murray JF, Matthay MA, Luce JM, et al. An expanded definition of the adult respiratory distress syndrome. Am Rev Respir Dis 1988;138:720-3.

13. Knaus WA, Draper EA, Wagner DP, et al. Apache II. A severity of disease classification system. Crit Care Med 1985;13:818-29.

14. Le Gall JR, Lemeshow S, Saulnier F. A new Simplified Acute Physiology Score (SAPS II) based on a European-North American multicenter study. JAMA 1993:270:2957-63

15. Linn S. The injury severity score — importance and uses. Ann Epidemiol 1995;5:440-6.

16. Luhr $\mathbf{O R}$, Antonsen $\mathrm{K}$, Karlsson $\mathrm{M}$, et al. Incidence and mortality after acute respiratory failure and acute respiratory distress syndrome in Sweden, Denmark, and Iceland. The ARF Study Group. Am J Respir Crit Care Med 1999;159:1849-61.

17. Hudson LD. Epidemiology of the adult respiratory distress syndrome. Semin Respir Crit Care Med 1994;15:254-9.
18. Montgomery AB, Stager MA, Carrico CJ, et al. Causes of mortality in patients with the adult respiratory distress syndrome. Am Rev Respir Dis 1985;132:485-9.

19. Milberg JA, Davis DR, Steinberg KP, et al. Improved survival of patients with acute respiratory distress syndrome (ARDS): 1983-1993. JAMA 1995;273:306-9.

20. Davidson TA, Rubenfeld GD, Caldwell ES, et al. The effect of acute respiratory distress syndrome on long-term survival. Am J Respir Crit Care Med 1999;160:1838-42.

21. Kallet RH, Jasmer RM, Pittet JF, et al. Clinical implementation of the ARDS network protocol is associated with reduced hospital mortality compared with historical controls. Crit Care Med 2005;33:925-9.

22. Hager DN, Krishnan, JA, Haydenm DL, et al. Tidal volume reduction in patient with acute lung injury when plateau pressures are not high. Am J Respri Crti Care Med 2005:172:1241-5

23. Ware LB. Prognostic determinants of acute respiratory distress syndrome in adults: impact on clinical trail design. Crit Care Med 2005;33:S217-22.

24. Trachsel D, McCrindle BW, Nakagawa S, et al. Oxygenation index predicts outcome in children with acute hypoxemic respiratory failure. Am J Respir Crit Care Med 2005; 172:206-11.

25. El-Khatib MF, Jamaleddine GW. A new oxygenation index for reflecting intrapulmonary shunting in patients undergoing open-heart surgery. Chest 2004;125:592-6.

26. Bayrakci B, Josephson C, Fackler J. Oxygenation index for extracorporeal membrane oxygenation: is there predictive significance? J Artif Organs 2007;10:6-9.

27. Brun-Buisson C, Minelli C. Bertolini G, et al. Epidemiology and outcome of acute lung injury in European intensive care units. Results from the ALIVE study. Intensive Care Med 2004;30:51-61

28. Rubenfeld GD, Caldwell E, Peabody E, et al. Incidence and outcomes of acute lung injury. N Engl J Med 2005;353:1685-93.

29. Estenssoro $\mathbf{E}$, Dubin A, Laffaire $\mathbf{E}$, et al. Impact of positive end-expiratory pressure on the definition of acute respiratory distress syndrome. Intensive Care Med 2003;29:1936-42.

\section{Lung alert}

\section{Inflammation caused by radiofrequency ablation for lung cancer is worse after radiotherapy and in large tumours}

The use of radiofrequency ablation (RFA) of solid primary and metastatic pulmonary tumours in poor-risk surgical patients is increasing. The authors report on percutaneous RFA with particular reference to inflammation-related complications in a series of 130 patients undergoing 327 ablation sessions using C-reactive protein (CRP) as a marker for inflammation. RFA was performed with CT guidance using the internally-cooled impedance-modulated Cool Tip system (Valleylab, Boulder, CO, USA). The mean lesion size was $2.4 \mathrm{~cm}$ and $71 \%$ were metastases. Two hundred and seventeen of the 327 sessions were preceded by previous surgery $(n=34)$, external beam radiotherapy (EBRT) $(n=17)$ or chemotherapy $(n=198)$.

Following RFA the mean CRP value increased from $1.3 \mathrm{mg} / \mathrm{dl}$ to $3.4 \mathrm{mg} / \mathrm{dl}$. The reported incidence of inflammation-related complications was $1.2 \%$, although five cases of abscess formation were not included in this group (revised incidence $2.7 \%$ ). This is lower than previously reported and could be due to continuing antibiotics $24-48 \mathrm{~h}$ after the procedure. There were two deaths $(0.6 \%) 8$ and 69 days after the procedure, both ascribed to radiation pneumonitis based on the clinical symptoms and distribution of pneumonic change on CT in patients who had previous EBRT. Using multiple logistic regression analysis, large tumour size and previous EBRT were significant risk factors while the number of punctures, type of tumour, chemotherapy or previous surgery were not.

The authors suggest that mechanical lung injury with RFA may worsen development of radiation pneumonitis, although the incidence here is very low. This is important, as there is increasing evidence of improved outcome in sequential treatment with EBRT and RFA. Based on these findings, it might be prudent to perform the EBRT after RFA. If performed afterwards, monitoring of KL-6 and cytokine levels may also be used to predict radiation pneumonitis before referral for RFA.

- Nomura M, Yamakado K, Nomoto Y, et al. Complications after lung radiofrequency ablation: risk factors for lung inflammation. $\mathrm{Br} J$ Radiol 2008;81:244-9.

\section{S Roy-Choudhury}

Correspondence to: Dr S Roy-Choudhury, Heart of England NHS Foundation Trust, Birmingham B9 5SS, UK; shuvrorc@ googlemail.com 